\title{
ESTRUTURA DE GOVERNANÇA: O CASO DO ARRANJO PRODUTIVO LOCAL (APL) DO SETOR DE CONFECÇÃO DE MARINGÁ (PR)
}

\author{
Antonio Carlos de Campos' \\ Jaime Graciano Trintin² \\ Vinícius Gonçalves Vidigal ${ }^{3}$
}

\section{Resumo}

Em estudo realizado anteriormente verificou-se a presença de um arranjo produtivo local (APL) da atividade de confecção no município de Maringá, no Estado do Paraná. O objetivo desse estudo consistiu em analisar as condições estruturais do setor de confecção neste município, buscando identificar e avaliar os elementos que compõem a estrutura de governança local, a qual conduz as decisões e atribuições dos agentes econômicos presentes nesse arranjo produtivo. Para tanto, utilizou-se como instrumental metodológico a pesquisa de campo junto a uma amostra de empresas e instituições do setor. Observou-se que as ações coordenadas são determinadas pelo SINDVEST (Sindicato do Vestuário de Maringá), que representa empresas filiadas e organiza reuniões com a participação de representantes das instituições de ensino superior (Universidade Estadual de Maringá e CESUMAR) e de capacitação empresarial e técnico (SEBRAE e SENAI, respectivamente). As propostas de ações conjuntas quase sempre são estimuladas a partir de editais específicos à APLs, juntamente à Secretaria de Estado do Planejamento e Coordenação Geral do Paraná (SEPL) e ao Sistema FIEP. Conclui-se, portanto, que apesar das ações em prol do setor, se faz necessária uma maior participação das micro e pequenas empresas no processo de tomada de decisões do arranjo, haja vista que os empresários

Doutor em Desenvolvimento Econômico pela Universidade Federal do Paraná (UFPR) e Professor do Departamento de Economia da Universidade Estadual de Maringá (UEM). e-mail: accampos@uem.br

Doutor em Ciências Econômicas pela Universidade Estadual de Campinas (UNICAMP). Professor do Departamento de Economia da Universidade Estadual de Maringá (UEM). email: jgtrintin@uem.br.

Mestrando em Economia Aplicada pela Universidade Federal de Viçosa (UFV). e-mail: viniciusgv@gmail.com. 
Estrutura de governança: o caso do Arranjo Produtivo Local (APL) do setor de confecção de Maringá (PR)

que comandam o setor representam, em sua grande maioria, empresas de médio e de grande porte.

Palavras-chave: arranjos produtivos locais, ações conjuntas, governança.

Classificações JEL: R11, L67.

\section{INTRODUÇÃO}

O arcabouço teórico apresentado neste trabalho provém de um tema que vem recebendo crescente atenção na literatura econômica, seja do ponto de vista teórico ou da observação empírica, que envolve as discussões acerca do formato de organização industrial dos Arranjos Produtivos Locais (APL). Como é de conhecimento de uma gama de pesquisadores da área de desenvolvimento regional e de organização industrial, a abordagem de arranjos produtivos locais tem origem nos estudos de Marshall sobre distritos industriais na Inglaterra ao final do século XIX. Tratam-se de aglomerações aonde se verifica especialização setorial e uma trajetória histórica de construção de identidade local em torno de uma atividade, sendo essa última formada a partir de uma base social e cultural comum.

A partir desse ambiente local, há crescente possibilidade de haver maior integração, cooperação e, principalmente, confiança entre os agentes envolvidos em determinado tipo de atividade econômica e, sendo assim, tornam-se mais propícios à construção de formatos organizacionais com características do que vem se denominando arranjo produtivo local. Portanto, o conceito de APL se baseia na proximidade geográfica entre as firmas, nas suas semelhanças históricas, culturais e sociais, ou seja, em elementos que estimulam um processo de interação entre as partes envolvidas, o qualque amplia a eficiência produtiva e proporciona um ambiente favorável à elevação da competitividade das empresas, seja via aumento da cooperação e das ações conjuntas, ou em razão da sinergia que se cria no local e que se direciona em prol do desenvolvimento de um determinado setor e/ou de uma atividade específica. Dessa forma, a dinâmica em arranjos produtivos locais tem auxiliado pequenas e médias empresas a melhorarem sua escala 
de produção, e sua eficiência na produção e na distribuição de produtos em mercados nacionais e globais.

É com esta abordagem que o setor de confecções do município de Maringá vem sendo tratado, haja vista a expressiva importância deste para o município, tanto no que se refere à empregabilidade quanto ao elevado número de estabelecimentos. As possibilidades de desenvolvimento de um aglomerado produtivo e de melhorias na sua competitividade estão associadas às condições de interação, às possibilidades de ações conjuntas e ao potencial de formulação de políticas públicas de apoio, o que torna necessário um estudo detalhado sobre esses fatores. Mas, além disso, faz-se relevante identificar as instituições e/ou empresas que coordenam as ações do arranjo produtivo de confecções em Maringá e, assim, esclarecer algumas questões, tais como: Como se constitui a governança local? Quais são os atores? As instituições de apoio são representativas? As pequenas empresas possuem voz e vez na tomada de decisão? A articulação entre empresas, por intermédio de instituições, tem gerado ações conjuntas?

A partir dessa perspectiva teórica, uma investigação sobre o modo de coordenação e participação dos diversos agentes presentes na atividade produtiva da confecção nesse APL mostra-se necessária, visto que são esses elementos determinantes para o desenvolvimento da capacidade competitiva das empresas e consolidação de um APL.

O objetivo deste estudo consistiu, portanto, em identificar e avaliar as posições nas quais se encontram as empresas e as instituições públicas e privadas locais na constituição e concretização da estrutura de governança local, considerando esse um passo fundamental à formulação de estratégias de desenvolvimento do conjunto da atividade e da região onde esta se faz presente.

\section{AGLOMERAÇÃO PRODUTIVA E ESTRUTURA DE GOVER- NANÇA}

Marshall (1982) destacou as vantagens proporcionadas pela concentração geográfica de firmas de determinada indústria. A proximidade geográfica, a especialização da mão-de-obra e o maior dinamismo também em outros mercados ligados ao processo produtivo, possibilitam a geração de 
economias externas aos produtores locais e conseqüentes ganhos de escala provenientes da redução nos custos de produção. Esse parece ser o ponto de partida para analisar as novas formas de organização das firmas.

Para as firmas, a proximidade geográfica possibilita o surgimento de outras atividades subsidiárias, fornecendo à indústria principal instrumentos e matérias-primas e, dessa forma, proporcionando economia de material. A presença de fornecedores de bens e serviços, portanto, se constitui em importante fonte de economias externas, especialmente quanto ao processo de conhecimento gerado através das relações entre firmas e seus fornecedores. Entretanto, os agentes locais poderiam fortalecer sua capacidade competitiva por meio de ações conjuntas deliberadas, tais como compras de matérias-primas, capacitação profissional, contratação de serviços especializados, entre outros.

É importante destacar que nessas localidades industriais ocorre um dinamismo nos mercados de trabalho e de insumos. No que se refere ao mercado de trabalho, observa-se que a indústria local oportuniza mercado para mão-de-obra especializada e, por outro lado, um número crescente de operários capacitados proporcionando, com isso, ganhos de aprendizagem. Nesse processo de interação, as técnicas e métodos de produção são difundidos e melhorados, uma vez que uma idéia torna-se fonte de outras novas idéias. "Os segredos da profissão deixam de ser segredos, e, por assim dizer, ficam soltos no ar, de modo que as crianças absorvem inconscientemente grande número deles" (MARSHALL, 1982, p. 234).

Segundo Schmitz (1997, p. 173), as ações conjuntas podem ser nãoplanejadas (incidentais) ou planejadas (conscientemente perseguidas) ${ }^{4}$. No primeiro caso, os ganhos de eficiência surgem de forma não intencional, ou seja, da própria existência da aglomeração industrial, a qual fornece custos reduzidos. No segundo caso, a eficiência coletiva planejada é resultante de ações conjuntas deliberadas de empresas e instituições locais. As ações conjuntas podem ainda ser divididas em dois grupos. As primeiras ocorrem através de firmas individuais cooperando entre si, ao passo que as do segundo grupo ocorrem através de grupos de firmas reunindo forças em associações empresariais, consórcio de produtores, sindicatos e outros. Portanto, as

A eficiência coletiva não-planejada e a eficiência coletiva planejada são conhecidas também por eficiência coletiva passiva e eficiência coletiva ativa, respectivamente (SCHMITZ e NADVI, 1999). 
relações entre os atores dos aglomerados industriais na busca de ações conjuntas significam muito mais do que economias externas planejadas. Elas representam, de fato, construções sociais específicas aos agentes locais, as quais não podem, assim, serem reproduzidas em outros contextos.

Normalmente, em seu início, os arranjos produtivos locais atendem às demandas locais, ou seja, a um mercado consumidor próximo à área de produção. Com a evolução e crescimento, a oferta se expande ao mercado nacional e internacional. Outra característica é que, em seu início, as empresas normalmente competem via preço e, com o amadurecimento, elas passam a competir através da inovação e da qualidade de seus produtos.

Pode-se dizer que as empresas localizadas em um mesmo território passam a apresentar algum tipo de vínculo entre si, gerando alguma sinergia entre elas e essa ligação entre elas proporciona certa condição que as possibilita auferir ganhos econômicos adicionais por estarem localizadas no mesmo espaço econômico.

Os governos, por sua vez, em seus vários níveis, também têm focado o local como objeto de políticas públicas. Estes, em parceria com agentes privados, procuram através de suas políticas melhorar as condições para o crescimento econômico desses arranjos produtivos. Tanto é que se tem estabelecido políticas de atração de investimentos e desenvolvimento tecnológico, a fim de favorecer o aumento do emprego e da geração de renda, bem como a elevação da competitividade das empresas em arranjos produtivos locais. Essas atuações, tanto pública quanto privada e público-privado, com foco no local, tendem a atenuar os problemas de baixo dinamismo das economias regionais.

\subsection{Estrutura de Governança}

Um dos principais focos para a compreensão da atividade industrial consiste na estrutura de governança da atividade produtiva, haja vista que representa as forças organizacionais e institucionais que condicionam o comportamento dos agentes na cadeia produtiva em nível local (CAMPOS, 2004).

Uma das primeiras contribuições para o tema foi o estudo de Storper \& Harrison (1991), os quais analisaram a governança num contexto de relações 
de poder estabelecidas num sistema de produção (cadeias de produção e de distribuição de mercadorias). Assim, a estrutura de governança é colocada como o grau de hierarquia e liderança na coordenação da relação entre as firmas presentes no sistema.

Os autores consideram importante questionar em que extensão e cenário os sistemas de produção são governadas por mecanismos de preço ou pelas hierarquias entres os agentes. Contudo, pode haver formas intermediárias de governança envolvendo maior nível de interação e cooperação entre as empresas, como apontam os próprios autores e Williamson (1985).

Storper \& Harrison (1991) baseiam-se na estrutura de "core and ring", que lida com a intensidade da hierarquia entre grandes firmas e seus fornecedores. "Core" refere-se a uma situação onde o poder é assimétrico ou algumas "firmas-núcleo" determinam a existência de outras, enquanto "ring" diz respeito ao oposto, onde o poder é simétrico ou a existência de um conjunto de firmas não é determinada por outra.

A partir disso, são apresentadas quatro tipologias de estruturas de governança envolvendo diferentes combinações dessas forças de poder. $\mathrm{Na}$ primeira, denominada "all ring no core", não há a presença de uma firma líder e, portanto, nenhuma hierarquia. Essa estrutura é exemplificada e pode ser verificada pela produção de filmes independentes em Hollywood ou na indústria têxtil de Prato (Itália). Vale-se lembrar que no caso do segundo exemplo, se tem observado a incorporação de fortes relações assimétricas entre as firmas locais ao longo de seu desenvolvimento nas décadas de 80 e 90 (LAZERSON e LORENZONI, 1999; e BELUSSI, 1999).

A segunda condição é a intermediária, com fraca hierarquia, onde se tem a combinação "core and ring”, e se pode observar a existência de alguma coordenação sistemática e assimetria entre os agentes. Entretanto, esse poder não permite à firma líder limitar nem determinar a existência de outras, uma vez que a primeira exerce influência sobre as últimas ao mesmo tempo em que depende delas.

A terceira estrutura é a "core-ring with lead firm". Nesta têm-se, também, assimetrias entre os agentes, mas há considerável hierarquia e a firma líder mostra-se dominante. São exemplos dessa estrutura os sistemas onde atuam companhias de produtos elétricos como General Eletric, Westinghouse, Sony e Philips. 
Por último, é apresentado aquilo que os autores chamaram de "all core" e, portanto, todas as unidades estão no núcleo. Nessa estrutura praticamente não se vê uma rede de empresas e a firma integrada verticalmente toma lugar na produção e distribuição das mercadorias.

O recente processo de desenvolvimento das forças produtivas capitalista tem mostrado um aumento de relações de hierarquia na cadeia de valor, a partir de um maior poder de determinadas empresas.

Neste sentido, Markusen (1995), nos seus estudos sobre as inter-relações entre diversas firmas, apresentou uma caracterização de redes locais hierarquizadas. A autora supunha que a análise das experiências dos distritos industriais não se estenderia a outras aglomerações em vários outros países. Ao contrário, pôde-se verificar o estabelecimento de um sistema "hub and spoke" (centro-radial), no qual uma grande firma coordena o processo produtivo e impõe os seus interesses sobre toda a cadeia, além de uma composição plataforma-satélite, onde as sedes dessas grandes empresas são externas ao aglomerado. Então, as relações que se configuram entre os agentes se dão apenas a partir das necessidades das firmas mais importantes, sendo que no segundo caso, as principais decisões da cadeia produtiva se dão fora do aglomerado. No entanto, mesmo que não haja relações cooperativas entre os agentes, as demais firmas locais terão a possibilidade de se beneficiar, mesmo que assimetricamente, do desenvolvimento da líder.

Ainda na perspectiva da investigação das hierarquias e formas de governança, o trabalho de Gereffi (1994) mostra-se como importante ferramenta de análise desses aspectos presentes na organização das cadeias produtivas globais. A idéia que se expõe é a de que a apropriação de valor na cadeia produtiva se dá de maneira assimétrica, em favor daqueles agentes que possuem capacidade de reunir ativos estratégicos.

Duas formas de cadeias produtivas globais, "producer-driven" $e$ “buyer-driven", são distinguidas pelo autor. As primeiras são dirigidas pelo produtor, ou seja, os ativos-chave referem-se à produção, especificamente ao desenvolvimento do produto e aos ativos comerciais. Por outro lado, as cadeias dirigidas pelo comprador envolvem na sua coordenação empresas que não desenvolvem atividades produtivas e cujo poder provém da detenção de ativos como marcas ou canais de comercialização e distribuição. Os compradores acabam por exercer forte influência sobre as estratégias 
dos produtores, mas sendo essenciais no aperfeiçoamento da qualidade dos produtos por meio de padrões técnicos de qualidade.

Nesse enfoque, Humphrey \& Schmitz (2000) estudaram como seria possível o desenvolvimento (upgrading) dos produtores aglomerados. Observou-se uma contradição nas relações entre os compradores e seus fornecedores. De um lado, os grandes compradores têm importância fundamental no processo de aprendizado por interação com os produtores locais, estabelecendo critérios técnicos e de qualidade. Neste caso, a aglomeração de produtores propicia maior facilidade na organização da cadeia (comercialização, assistência técnica, etc), ou seja, maior eficiência e menores custos. De outro lado, essas interações ficam restritas a esfera da produção. Mesmo que venham a desenvolver atividades inovativas, os produtores não conseguem avançar na geração de ativos que adicionam valor a esse processo, tais como desenvolvimento do produto, canais de comercialização e distribuição. Ao mesmo tempo, isso garante a capacidade de comando da cadeia produtiva como um todo por parte dos grandes compradores internacionais (SUZIGAN, GARCIA e FURTADO, 2002). Portanto, parte dos benefícios que são gerados pela aglomeração dos produtores, cujas naturezas são as economias externas incidentais e o maior escopo para o estabelecimento e a manutenção de ações conjuntas, não são apropriados pelas empresas locais.

A partir dessa perspectiva, os mesmos Humphrey \& Schmitz (2000) apresentaram sua análise sob relações em rede ("network"), quase-hierarquia e hierarquia entre os agentes da cadeia. A primeira diz respeito a uma coordenação que se dá por meio de cooperação numa rede de firmas com poder "mais ou menos iguais". Na quase-hierarquia, o que se tem é um elevado grau de controle do comprador sobre o fornecedor, há uma clara relação de subordinação. Aqui, as firmas líderes podem exercer forte influência sobre as estratégias das demais que compõem o sistema, o que vem a ser prejudicial ao seu desenvolvimento em diversas situações. Finalmente, a hierarquia trata da relação onde o comprador toma propriedade direta das operações de produção, sendo essa totalmente integrada.

As estruturas de governança também podem ser observadas em cadeias no formato dos distritos industriais marshallianos e arranjos produtivos locais. Logo, Humphrey \& Schmitz (2000) afirmam a existência de formas 
de governança local, pública e privada, relevantes ao desenvolvimento dos produtores de uma aglomeração. A partir disso, ações definidas pelos agentes locais com vistas à evolução da atividade produtiva podem vir a se somar aos benefícios oriundos das economias externas incidentais.

Essas ações podem ser coordenadas pelo setor público, com políticas de desenvolvimento e de ampliação da competitividade das firmas, ou agentes privados presentes no local, com a criação de sindicatos e liderança de uma firma.

A governança local atribuída ao setor público relaciona-se a atuação dos governos locais no estabelecimento de órgãos voltados ao desenvolvimento dos produtores locais, tais como centros de treinamento de mão-deobra, de prestação de serviços tecnológicos e agências governamentais de desenvolvimento. O setor público tem sido apontado por diversos estudos como importante apoio à atividade produtiva (Quadro 1).

\begin{tabular}{|l|l|l|}
\hline & Nível Local & Nível Global \\
\hline $\begin{array}{l}\text { Governança } \\
\text { Privada }\end{array}$ & $\begin{array}{l}\text { Associações empresa- } \\
\text { riais locais } \\
\text { Cluster hub-and-spoke }\end{array}$ & $\begin{array}{l}\text { Cadeia global dirigida pelo com- } \\
\text { prador } \\
\text { Cadeia global dirigida pelo pro- } \\
\text { dutor }\end{array}$ \\
\hline $\begin{array}{l}\text { Governança } \\
\text { Pública }\end{array}$ & $\begin{array}{l}\text { Agências governamen- } \\
\text { tais locais e regionais }\end{array}$ & $\begin{array}{l}\text { Regras da OMC } \\
\text { Regras nacionais e supranacio- } \\
\text { nais referência global }\end{array}$ \\
\hline $\begin{array}{l}\text { Governança } \\
\text { Pública-Privada }\end{array}$ & $\begin{array}{l}\text { Redes de políticas locais } \\
\text { e regionais }\end{array}$ & $\begin{array}{l}\text { Padrões internacionais } \\
\text { Campanhas de organizações não } \\
\text { governamentais internacionais }\end{array}$ \\
\hline
\end{tabular}

Quadro 1 - Categorias de governança da atividade econômica públicaprivada e local-global

Fonte: Humphrey \& Schmitz (2000).

No caso da governança local privada, enfatiza-se a atuação de associações de classe e de agencias locais de desenvolvimento. Essas instituições 
podem atuar no processo de desenvolvimento da atividade produtiva procedendo com medidas que melhoram a produtividade e competitividade das empresas. Algumas dessas ações correspondem ao fornecimento de infra-estrutura e prestação de serviços, criação de centros de treinamento e de agência provedora de informações tecnológicas e de mercado.

De acordo com Humphrey \& Schmitz (2000), as formas de governança mais comuns são híbridas, envolvendo participação pública e privada, em âmbito local, por meio de redes de políticas locais e regionais e sua existência é importante para estimular os agentes do sistema produtivo a manter relações de cooperação e atuação conjunta e, assim, tornam-se decisivas no aproveitamento da condição de aglomerado.

\section{FONTE DE DADOS E CARACTERIZAÇÃO DA ATIVIDADE DE CONFECÇÃO}

Os objetivos anteriormente propostos exigiram, primeiramente, a utilização de dados secundários provenientes da Relação Anual de Informações Sociais do Ministério do Trabalho e Emprego (RAIS/MTE) como base para a caracterização da atividade de confecções no município.

Em um segundo momento, conduziu-se para a pesquisa de campo, no ano de 2008, com a aplicação de questionários junto a empresas e instituições do setor de confecções no município de Maringá. As questões elaboradas incorporam elementos de outros questionários já constituídos e empregados em casos semelhantes em diversas regiões do Brasil. As informações obtidas nas entrevistas possibilitaram a identificação e avaliação de características das várias confecções presentes no arranjo produtivo, assim como das relações entre essas e outros agentes do aglomerado, sobretudo no que se refere aos aspectos de hierarquia e de tomada de decisão.

A seleção do universo de empresas pesquisadas baseou-se na Classificação Nacional de Atividades Econômicas (CNAE 1.0) do IBGE 5 , sendo escolhidas as classes 18112, 18120, 18139, 18210 e 18228, referentes à confecção de artigos do vestuário. Em relação à amostra utilizada, foi constituída a partir da reunião de cadastros de instituições públicas e privadas. Visitou-se, também, instituições de ensino superior, como a Univer-

Ver http://www.cnae.ibge.gov.br/ 
sidade Estadual de Maringá (UEM) e o Centro Universitário de Maringá (CESUMAR), e instituições de capacitação empresarial e técnica, como o SEBRAE (Serviço Brasileiro de Apoio às Micro e Pequenas Empresas) e o SENAI (Serviço Nacional de Aprendizagem Industrial), respectivamente. Além dessas, integraram o estudo o Sindicato da Indústria do Vestuário de Maringá (SINDVEST), o Sindicato dos Trabalhadores nas Indústrias de Confecções de Maringá (SINCONFEMAR) e a Prefeitura Municipal de Maringá, através da Secretaria de Desenvolvimento Econômico.

Informações do IBGE (2008a) demonstram que, em 2007, Maringá contava com uma população de 325.968 habitantes, a qual é quase em sua totalidade urbana (98\%). A população urbana está empregada, em sua maior parte, na atividade de prestação de serviços e na indústria. A composição do PIB (Produto Interno Bruto) municipal, em 2004, apresentava predominância do setor de serviços com representação de aproximadamente 59,0\%, seguido pela indústria e pela agropecuária, com $39,0 \%$ e $2,0 \%$, respectivamente (IBGE, 2008b). Pode se observar que esse padrão é semelhante aos de grandes centros urbanos do país.

Quando se coloca em evidência o PIB de Maringá em relação ao do estado do Paraná, constata-se que esse representava, em 2004, o equivalente a 3,0\% do total. No entanto, ao se comparar o PIB industrial este representava $7,8 \%$, enquanto o de serviços participava com $9,1 \%$, isto é, o terceiro maior do estado. Em outros termos, o município se posiciona de forma razoável na economia do estado (Tabela 1).

Uma observação importante sobre a participação deste município no PIB estadual é que o mesmo vem perdendo participação relativa no conjunto estadual em razão do grande crescimento industrial da região metropolitana de Curitiba, fruto dos investimentos realizados no setor industrial no decorrer da década de noventa e, também, da expansão que se verifica em Foz do Iguaçu. 
Tabela 1 - Participação relativa dos municípios no PIB do Estado do Paraná, 2004

\begin{tabular}{lrcrrc}
\hline Município & Agropecuária & Indústria & Serviços & PIB & $\begin{array}{c}\text { Partici- } \\
\text { pação } \\
\text { no PIB } \\
\text { do Para- } \\
\text { ná (\%) }\end{array}$ \\
\hline Curitiba & 1.009 .519 & 7.619 .107 .130 & 10.490 .728 .394 & 19.109 .743 .775 & 17,7 \\
Araucária & 63.573 .410 & 3.604 .723 .988 & 1.779 .375 .868 & 6.697 .618 .862 & 5,3 \\
$\begin{array}{l}\text { São José dos } \\
\text { Pinhais }\end{array}$ & 46.936 .126 & 3.232 .140 .568 & 1.379 .057 .009 & 5.683 .425 .065 & 4,5 \\
Paranaguá & 4.027 .637 & 2.757 .823 .961 & 1.441 .330 .329 & 4.314 .316 .736 & 4,1 \\
Londrina & 190.729 .920 & 1.712 .829 .589 & 2.294 .325 .891 & 4.237 .121 .015 & 4,1 \\
Ponta Grossa & 189.683 .879 & 2.080 .802 .338 & 1.217 .203 .404 & 3.725 .520 .031 & 3,4 \\
Foz do Iguaçu & 17.242 .372 & 2.584 .192 .318 & 857.566 .263 & 3.668 .443 .675 & 3,4 \\
Maringá & 62.497 .987 & 1.215 .808 .929 & 1.837 .529 .988 & 3.209 .019 .137 & 3,0 \\
Cascavel & 340.382 .377 & 734.550 .930 & 1.187 .893 .888 & 2.261 .031 .935 & 2,2 \\
\hline $\begin{array}{l}\text { Demais } \\
\text { municípios }\end{array}$ & 17.929 .113 .173 & 15.422 .899 .961 & 20.199 .418 .247 & 53.551 .430 .808 & 52,3 \\
\hline
\end{tabular}

Fonte: IBGE (2008b).

Em relação ao número de trabalhadores por setor de atividade econômica no município de Maringá, apresentado na Tabela 2, observa-se que é o setor de serviços o que mais proporciona empregos (44,6\%), seguido pela indústria $(23,3 \%)$ e pela agropecuária $(0,8 \%)$.

Tabela 2 - Participação relativa dos setores de atividade no emprego do município de Maringá, 2004

\begin{tabular}{lcc}
\hline Atividade & Trabalhadores & $\begin{array}{c}\text { Participação } \\
\text { relativa (\%) }\end{array}$ \\
\hline Serviços & 43.024 & 44,6 \\
Comércio & 26.531 & 27,5 \\
Indústria & 22.454 & 23,3 \\
Construção civil & 3.736 & 3,9 \\
Agropecuária, extração vegetal, caça e pesca & 743 & 0,8 \\
\hline Total & 96.488 & 100 \\
\hline
\end{tabular}

Fonte: BRASIL/RAIS (2008). 
Uma relação entre o número de empregos de Maringá e do Estado do Paraná aponta que Maringá responde por 4,5\% do emprego da indústria de transformação paranaense e por $4,7 \%$ do emprego total estadual. Isso demonstra a importância das atividades, principalmente industriais, desenvolvidas no município no que diz respeito à geração de postos de trabalho, principalmente do setor de confecções que é um dos principais na geração de emprego e renda neste município.

O setor de confecções, foco de nossa pesquisa, é representado nesse estudo pela Divisão 18 da classificação CNAE, a qual é denominada confecção de artigos do vestuário e acessórios. O Estado do Paraná concentrava, em 2006, 9,1\% dos estabelecimentos da atividade de confecção brasileira, com um total de 3.666 empresas. Numa análise da inserção de Maringá no total do Estado, nota-se relativa importância da indústria de confecção do município, visto que $12,5 \%$ das empresas desse setor estão localizados no APL de Maringá, ficando a frente dos municípios de Cianorte $(11,1 \%)$, Apucarana (10,8\%), Curitiba $(8,6 \%)$ e Londrina $(6,6 \%)$, conforme dados da RAIS (BRASIL/RAIS, 2008).

A atividade de confecção de artigos do vestuário e acessórios é uma das atividades industriais mais importantes no município de Maringá, com 502 estabelecimentos $(29,5 \%)$, a frente da indústria de móveis e de produtos alimentícios e bebidas (Tabela 3 ).

Tabela 3 - Número de estabelecimentos e participações relativas, por Divisão CNAE, em Maringá - 2006

\begin{tabular}{lcc}
\hline Atividade Industrial (Classificação CNAE 2 dígitos) & $\begin{array}{c}\text { Estabele- } \\
\text { cimentos }\end{array}$ & $\begin{array}{c}\text { Participação } \\
\text { relativa (\%) }\end{array}$ \\
\hline DIVISAO 18 - Confecção de artigos do vestuário e acessórios & 502 & 29,5 \\
DIVISAO 15 - Fabricação de produtos alimentícios e bebidas & 192 & 11,3 \\
DIVISAO 36 - Fabricação de moveis e indústrias diversas & 170 & 10,0 \\
DIVISAO 28 - Fabricação de produtos de metal - exclusive & 159 & 9,3 \\
$\quad$ máquinas e equipamentos & 107 & 6,3 \\
DIVISAO 22 - Edição, impressão e reprodução de gravações & 574 & 33,7 \\
Demais Divisões & 1704 & 100 \\
\hline Total & & \\
\hline
\end{tabular}

Fonte: BRASIL/RAIS (2008). 
A divisão 18 é também uma daquelas que mais empregam no município, com um número superior a cinco mil trabalhadores, correspondendo a $24,5 \%$ dos postos de trabalho da indústria local. O único setor que possui número de trabalhadores superior ao do setor de confecção é o de fabricação de produtos alimentícios e bebidas, que responde por $30,7 \%$ do total (Tabela 4 ).

Tabela 4 - Número de empregos e participações relativas, por Divisão CNAE, em Maringá - 2006

\begin{tabular}{lcc}
\hline Atividade Industrial (Classificação CNAE 2 dígitos) & Empregos & $\begin{array}{c}\text { Participação } \\
\text { relativa (\%) }\end{array}$ \\
\hline DIVISAO 15 - Fabricação de produtos alimentícios e bebidas & 6895 & 30,7 \\
DIVISAO 18 - Confecção de artigos do vestuário e acessórios & 5514 & 24,5 \\
DIVISAO 36 - Fabricação de moveis e indústrias diversas & 1697 & 7,6 \\
DIVISAO 17 - Fabricação de produtos têxteis & 1377 & 6,1 \\
DIVISAO 28 - Fabricação de produtos de metal - exclusive & 1235 & 5,5 \\
$\quad$ máquinas e equipamentos & 1127 & 5,0 \\
DIVISAO 25 - Fabricação de artigos de borracha e plástico & 1064 & 4,7 \\
DIVISAO 22 - Edição, impressão e reprodução de gravações & 1062 & 4,7 \\
DIVISAO 29 - Fabricação de maquinas e equipamentos & 2503 & 11,1 \\
Demais Divisões & 22474 & 100 \\
\hline Total
\end{tabular}

Fonte: BRASIL/RAIS (2008).

Assim, dada a importância da atividade de confecção de artigos do vestuário e acessórios no município de Maringá, especialmente quanto a sua capacidade de empregabilidade, tornam-se necessários estudos que possam evidenciar os determinantes da coordenação e das estratégias adotadas no arranjo produtivo local, com vistas ao seu grau de desenvolvimento.

\section{AESTRUTURA DE GOVERNANÇA DO APL DE CONFECÇÃO NO MUNICÍPIO DE MARINGÁ}

A estrutura de governança encontrada no aglomerado produtivo da indústria de confecção de Maringá mostra-se baseada fundamentalmente 
na governança privada local. Trata-se de uma condição onde há a presença de associações empresariais locais e a organização se dá no formato de rede (network). Nesse caso, há uma coordenação onde as firmas apresentam poder em níveis semelhantes.

A visita às empresas demonstrou que há certo nível de interação entre os empresários, especificamente na obtenção de informações sobre inovações tecnológicas, novos produtos e tendências de moda. Uma ação deliberada entre a maioria deles é a participação coletiva em feiras e congressos no Brasil e no exterior com esse mesmo objetivo. O caso das viagens ao exterior consiste em fonte importante de conhecimento e gera significativas economias externas para as empresas locais.

Porém, o maior exemplo de articulação entre as firmas locais proporcionado pelo sindicato patronal, o SINDVEST (Sindicato da Indústria do Vestuário de Maringá). Este desenvolve ações que se estende para outras empresas localizadas em outros municípios próximos a Maringá e fortemente concentrados na região Norte Central do Estado do Paraná, com cerca de 170 empresas filiadas e cinco shoppings atacadistas. Os empresários têm o sindicato como principal meio de associação, sendo que é este o centralizador e ator principal na condução das iniciativas conjuntas do setor e sua principal forma de representação.

O SINDVEST tem como principais atividades a organização de encontros para definição de projetos e estratégias para o setor, o oferecimento de cursos e treinamentos para os empresários e para a mão-de-obra, além de promover eventos tais como feiras, exposições e viagens para feiras em outras localidades e realização de parcerias para participação em projetos que visem melhorar a produtividade e competitividade das empresas. Essas ações são resultados da interação desta instituição com as demais, notadamente com o SENAI, o SEBRAE e, ultimamente, com a Universidade Estadual de Maringá (UEM), que vem desenvolvendo dois importantes projetos para o setor.

O arranjo produtivo de confecção de Maringá é composto na sua maior parte por micro e pequenas empresas $(98,4 \%)$, enquanto as restantes - oito empresas - são de médio porte. Entretanto, observou-se que embora existam algumas firmas líderes, de maior porte, que comandam o setor, as menores ocupam cadeira e são representadas na estrutura de governança local, haja 
vista que participam da mesma. Outras instituições se fazem presentes no arranjo e na estrutura de governança local e apresentam, inclusive, relação estreita com o SINDVEST, especialmente no sentido de realizar as demandas apresentadas por ele. Estão entre elas o o SENAI, o SEBRAE e o SINCONFEMAR, além das instituições de ensino superior UEM e CESUMAR. A Figura 1 apresenta o grau dos vínculos estabelecidos entre o setor de confecção e os demais atores atuantes no arranjo.

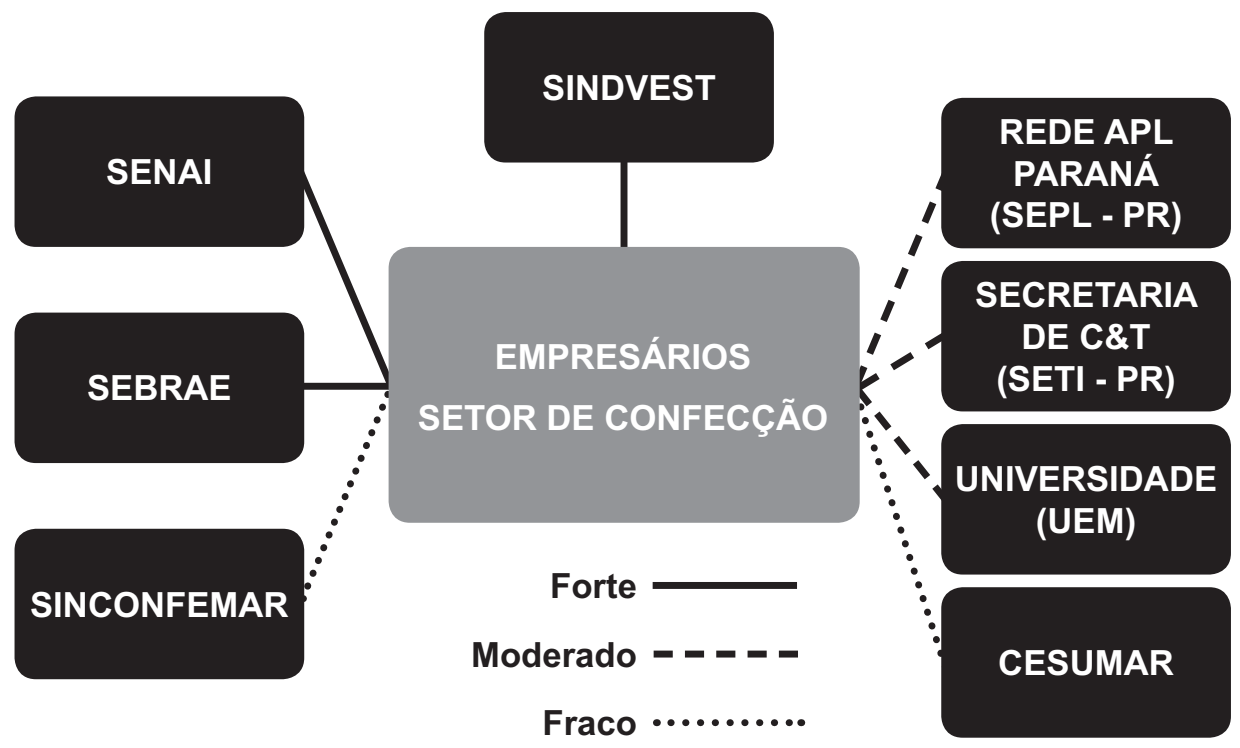

Fonte: Elaboração dos autores.

Figura 1 - Empresários do setor de confecção e principais vínculos com atores do APL de confecção de Maringá - 2008

O SENAI, integrante do sistema FIEP (Federação das Indústrias do Estado do Paraná), representa um dos mais importantes parceiros do SINDVEST, no que diz respeito à organização de cursos direcionados à confecção. Há vários anos a entidade tem qualificado a mão-de-obra para atuar no processo industrial. Entre os cursos oferecidos aos trabalhadores do setor estão o Curso Técnico em Confecção Industrial, com formação voltada ao planejamento, programação e controle da produção. 
Deve-se destacar a recente inauguração, em junho de 2008, do Centro Tecnológico de Maringá (CTM), a partir de parceria entre o próprio SINDVEST e o Sindicato da Indústria Metal-mecânica de Maringá (SINDIMETAL). O corpo de professores provém do SENAI e o centro conta com recursos do Governo Federal (Fundo Nacional de Desenvolvimento da Educação-Ministério da Educação). Ao todo, são 13 cursos de qualificação voltados à atividade confeccionista e um curso de técnico em confecção industrial. Isso vem confirmar que os esforços conjuntos do setor são centralizados pelo SINDVEST e enfocam, basicamente, a realização de cursos de formação técnica.

Dentro desse círculo de instituições privadas que contribuem com o setor encontra-se ainda o SEBRAE. O apoio prestado às empresas vai desde a capacitação de pessoal e fornecimento de assistência gerencial a estudos de mercado e de viabilidade econômica, além da organização de alguns eventos. Por se tratar de um setor com predominância de micro e pequenas empresas, o SEBRAE é muito demandado, sobretudo para a prestação de consultoria empresarial e de orientação técnica, formulação de projetos e desenvolvimento de novos produtos. Entretanto, alguns empresários cobram avanços nas técnicas de gestão, pois os cursos oferecidos não estariam atendendo às suas expectativas.

Ainda tratando de instituições privadas presente no arranjo produtivo, tem-se o SINCONFEMAR. Trata-se do sindicato dos trabalhadores das confecções e que, assim como SINDVEST (representação dos empresários), promove cursos de capacitação técnica para os associados e eventos diversos. Todavia, o sindicato exerce fundamentalmente o papel de prestador de serviços aos trabalhadores. As principais formas de apoio são a assistência jurídica, por meio da resolução de questões trabalhistas, e também consultas médicas e odontológicas.

O pólo confeccionista de Maringá tem, por outro lado, importantes atores públicos como parte integrante do seu ambiente institucional. São instituições que não se encontram no local, mas que têm exercido influência sobre o setor. Nesse sentido, pode-se citar o papel desempenhado pela Rede APL Paraná, organizada pela Secretaria de Estado do Planejamento e Coordenação Geral (SEPL) desse estado. Trata-se de um grupo composto por representantes do governo estadual, universidades, bancos e empresários, que tem estudado e buscado apontar quais os problemas e as possíveis 
soluções, no âmbito da política pública, para os arranjos. O APL de confecção de Maringá está entre os 22 casos estudados pela Rede APL e entre os 11 desses casos que já foram eleitos pelo Governo Federal (Ministério do Desenvolvimento, Indústria e Comércio Exterior - MDIC) como prioridade no país e, assim, integra um plano de política mais amplo que implica em recebimento de apoios técnico e financeiro.

A presença de instituições de ensino superior em Maringá tem colaborado para a interação entre as mesmas e as empresas de confecção. Os empresários do setor têm buscado auxílio junto à universidade como meio de solucionar problemas com os quais se deparam no decorrer do processo produtivo. Isso demonstra a existência de laços, embora ainda incipientes, entre as empresas e a Universidade Estadual de Maringá (UEM), dados o potencial da mesma em relação a pesquisas e os seus diversos departamentos ligados ao desenvolvimento de tecnologias, como o de engenharia de produção (confecção industrial) em Maringá e de engenharia têxtil em Goioerê, e dedicados à atividade de confecção, como é o caso dos cursos de moda e design, localizados em Cianorte ${ }^{6}$. Há ainda um curso de moda no CESUMAR, o qual também apresenta vínculos com o setor, haja vista a participação de membros desta instituição privada na composição da estrutura de governança local, bem como na elaboração de eventos.

Além desses cursos diretamente relacionados à atividade confeccionista, verificou-se a existência de alguns projetos de pesquisa nos departamentos de Engenharia de Produção, Engenharia Química e Economia da UEM, os quais têm a confecção como objeto de estudo. Os objetivos dos projetos envolvem respectivamente a implantação de sistema de avaliação de desempenho da produção em empresas de confecção industrial, o desenvolvimento de novas tecnologias para o tratamento de efluentes das lavanderias industriais e, por fim, a avaliação estrutural do setor de modo a subsidiar a formulação de políticas de apoio destinadas ao mesmo. Além disso, outros projetos têm sido propostos às agências de fomento, elaborados conjuntamente com os empresários, incentivados pelo SINDVEST, propondo ações de interesse de todo o arranjo.

Mais recentemente, a Secretaria de Ciência, Tecnologia e Ensino Superior do Paraná (SETI) formulou um edital de programa de Extensão

\footnotetext{
Município com tradição na atividade confeccionista e que se encontra a aproximadamente 60 km de Maringá.
} 
Tecnológica Empresarial, com o objetivo de aproximar as universidades e faculdades públicas estaduais e os micro e pequenos empresários organizados em APLs. O investimento nos projetos é de aproximadamente 6 milhões de reais e destina-se a fomentar o surgimento e o desenvolvimento de micro e pequenos empreendimentos, propiciando condições de acesso a conhecimentos tecnológicos e de gestão (PARANÁ, 2008). Trata-se de um esforço deliberado de um agente público com o objetivo de estimular o desenvolvimento de atividades importantes na geração de empregos e promover uma descentralização dos investimentos públicos, contribuindo com a inserção de atividades industriais aglomeradas num contexto maior da produção.

\section{CONSIDERAÇÕES FINAIS}

O presente estudo buscou identificar e avaliar as posições nas quais se encontram as empresas e as instituições públicas e privadas locais na constituição e concretização da estrutura de governança do arranjo produtivo local de confecção em Maringá.

Observou-se que há diversas instituições locais estabelecendo relação direta com a atividade. As mais participativas são o SINDVEST, o SENAI e o SEBRAE, sendo aquelas que apresentam maior envolvimento com a atividade, especialmente no que se refere à definição de estratégias implementadas pelo segmento. Além dessas, fazem-se presentes também instituições de ensino superior, especialmente a Universidade Estadual de Maringá, que tem intensificado sua participação, particularmente por meio de proposições de projetos de pesquisa desenvolvidos conjuntamente com empresários do setor.

Há uma sinalização de descentralização das medidas de apoio ao setor, a partir de ações do governo estadual por meio da Secretaria de Estado do Planejamento e Coordenação Geral (SEPL), apoiando diretamente os empresários e, mais recentemente, da Secretaria de Estado da Ciência, Tecnologia e Ensino Superior (SETI), incentivando maior envolvimento entre pesquisadores (principalmente da UEM) e empresários, na maioria dos casos representados pelo SINDVEST.

O SINDVEST é a instituição mais representativa. Mesmo sendo o sindicato dos empresários do setor de confecção local, verificou-se fragilidade quanto à participação das micro e pequenas empresas no processo de coordenação das atividades e decisões do APL. Portanto, faz-se necessário 
um maior grau de participação das micro e pequenas empresas no processo de tomada de decisões do arranjo, visando um aperfeiçoamento do conjunto da atividade e da região aonde esta se faz presente.

\title{
GOVERNANCE STRUCTURE OF LOCAL PRODUCTIVE ARRANGEMENT: A CASE STUDY OF CLOTHING INDUSTRY IN MARINGÁ - PARANÁ STATE
}

\begin{abstract}
Previous study verified the presence of a local productive arrangement in the clothing activity in Maringá, Paraná State. The objective of this study consisted in analyzing the structural conditions of the clothing sector in this town, identifying and evaluating the elements that compose the local governance structure, which conducts the decisions and functions of the economic agents present in this productive arrangement. The methodology refers to field research conducted among a sample of companies and institutions. The sector actions are determined by SINDVEST (Maringá Clothing Union) which represents the firms and organizes meetings with participation of universities (State University of Maringá and CESUMAR) and other institutions (SEBRAE and SENAI). The proposals of joint actions are almost always stimulated by the Secretary of State for Planning and General Coordination (SEPL) and Sistema FIEP. The conclusion is that it is required a greater participation degree of micro and small companies in the process of decision-making in the arrangement, once most of the entrepreneurs that command the sector represent medium and big companies.
\end{abstract}

Keywords: local productive arrangements, joint actions, governance.

\section{REFERÊNCIAS}

BELUSSI, F. Policies for development of knowledge-intensive local production system. Cambridge Journal of Economics, v. 23, p. 729-747, 1999. 
BRASIL. Ministério do Trabalho e Emprego. Relação Anual de Informações Sociais (RAIS). Disponível em: $<$ http://www.mte.gov.br/pdet/Acesso/ RaisOnLine.asp> Acesso em: mai. 2008.

CAMPOS, A. C. Arranjos Produtivos no Estado do Paraná: o caso do município de Cianorte. (Tese de Doutorado), Curitiba, UFPR, 2004.

GEREFFI, G. The organization of buyer-driven global commodity chains: how U.S. retailers shape overseas production networks. In: GEREFFI, G.; KORZENIEWICZ, M. (Org.). Commodity chains and global capitalism. Westport: Praeger, 1994.

HUMPHREY, J.; SCHMITZ, H. Governance and upgrading: linking industrial cluster and global value chain research. IDS Working Paper, $\mathrm{n}$. 120, nov. 2000.

IBGE. Instituto Brasileiro de Geografia e Estatística. Cidades@. Disponível em: $<$ http://www.ibge.gov.br/cidadesat $>$ Acesso em: mai. 2008a.

IBGE. Instituto Brasileiro de Geografia e Estatística. Produto Interno Bruto dos Municípios: 2004. Disponível em: $<\mathrm{ftp}: / / \mathrm{ftp}$.ibge.gov.br/Pib_Municipios/2004> Acesso em: mai. 2008b.

LAZERSON, M.; LORENZONI, G. The firms that feed industrial districts: a return to the Italian source. Industrial and Corporate Change, v. 8, n. 2, jun, 1999.

MARKUSEN, A. Áreas de atração de investimentos em um espaço econômico cambiante: uma tipologia de distritos industriais. Nova Economia, Belo Horizonte, v. 5, n. 2, dez, 1995.

MARSHALL, A. Princípios de Economia: tratado introdutório. São Paulo: Abril Cultural, vol. I, p. 231-238, 1982. 
PARANÁ. Secretaria de Estado de Ciência, Tecnologia e Ensino Superior (SETI). Disponível em: <http://fundacaoaraucaria.org.br/chamadas/ chamadas2008/PETE/PETE2008.htm> Acesso em: ago. 2008.

SCHMITZ, H. Eficiência coletiva: caminho de crescimento para a indústria de pequeno porte. Ensaios FEE, Porto Alegre, v. 18, n.2 p. 164-200, 1997.

STORPER, M.; HARRISON, B. Flexibility, hierarchy and regional developments: the changing structure of industrial production systems and their forms of governance in the 1990s. Research Policy, NorthHolland, v. 20, n. 5, 1991.

SUZIGAN, W; GARCIA, R; FURTADO, J. Governança de sistemas de MPMEs em clusters industriais. Setembro, 2002. Disponível em $<\mathrm{http}: / /$ www.ie.ufrj.br/redesist> Acesso em: mar. 2007.

WILLIAMSON, O.E. The economic institutions of capitalism. New York: Free Press, 1985. 